\title{
Consumer species have limited and variable roles in community organization on a tropical intertidal shore
}

\author{
K. R. S. Sauer Machado ${ }^{1,2}$, A. R. O. Chapman ${ }^{2, *}$, R. Coutinho ${ }^{1}$ \\ ${ }^{1}$ IEAPM, Rua Kioto 253, Arraial do Cabo, 28910, Brazil \\ ${ }^{2}$ Department of Biology, Dalhousie University, Halifax, Nova Scotia, Canada B3H 4J1
}

\begin{abstract}
From a list of specific predictions put forward in 1992, we tested the proposition that, in physically benign environments where herbivorous fishes are abundant, consumer pressure will be the main structuring force in rocky shore communities. Manipulation experiments were done in an intertidal community situated $150 \mathrm{~km}$ east of Rio de Janeiro, Brazil. The presence or absence of basal species (2 types: red algal turf and colonial coelenterate) was tested in combination with the presence or absence of 3 common consumer groups (amphipods, crabs, fishes). The design allowed us to separate the effects of pre-emptive competition and consumer pressure on the abundances of species at the lowest trophic level. Although herbivores were abundant, most effects of consumer species were not significant. Of 16 data sets involving herbivores, 11 were not significant. Pre-emptive competition (detected as a response to presence or absence of basal species) had a major effect in all but 1 case. Further, the effects of grazers were not consistent. Herbivores had no significant effects on Enteromorpha abundance in clearings made in red algal turf patches. In similar clearings made in Zoanthus patches, grazers reduced the cover of Enteromorpha. In contrast, cover of Ulva was enhanced by fishes and crabs in both patch types. Amphipods also increased the abundance of Ulva, but only in clearings in Zoanthus patches. The roles of consumers were therefore inconsistent. Conversely, competitive effects were nearly always significant, consistent, and responsible for most of the variance in the dependent variables tested. Our results show that there is no basis for the generalization which proposes that, in benign tropical shore environments where herbivorous fish are abundant, the effect of consumers dominates community structure, and that competition is an unimportant structuring agent.
\end{abstract}

KEY WORDS: Competition · Community organization · Experimental · Grazing · Intertidal - Tropics

\section{INTRODUCTION}

In the late 1970 s a comprehensive series of experiments was carried out on the shores situated in the Bay of Panama (Menge \& Lubchenco 1981, Menge et al. 1983, 1985, 1986a, b, Lubchenco et al. 1984). On the islands studied, the shores were covered by a pavement of crustose algae, with only 0 to $17 \%$ cover by foliose species. Mobile carnivores and herbivores were very abundant and experimental exclusions clearly showed that these species removed most sessile foliose

·Addressee for correspondence. E-mail: achapman@is.dal.ca forms. It appeared that consumer pressure kept the abundances of sessile forms so low that competition for space was minimal and therefore had a marginal effect on community organization (Menge et al. 1986b).

Apart from the work in the Bay of Panama, there have been remarkably few experimental studies of community organization on intertidal rocky shores in the tropics, though an extensive program is now developing on shores around Hong Kong (Williams 1994). In spite of the dearth of information, Brosnan (1992) developed a series of generalizations about the organization of tropical intertidal communities on rocky shores. She suggested that it is only the 'relative importance' of ecological processes which differs 
among temperate and tropical shores. The same kinds of ecological interactions occur in tropical and temperate latitudes, but the relative contribution of each to community structure varies across latitudes. Specifically, Brosnan (1992) referred to the importance of competition among basal sessile species versus the effects of consumer species (especially fish) as structuring agents of algal assemblages. In the tropics, herbivorous fish forage in the intertidal zone and Brosnan (1992) concluded that these grazers are primarily responsible for patterns of algal distribution and abundance. Fish have a much more limited role on temperate shores. Brosnan (1992) predicted that, where grazing fish are abundant (i.e. in the tropics), algal growth rates will not compensate for herbivory, and shores will appear bare or dominated by resistant crustose forms. Further, shores subject to fish grazing should have a less patchy appearance than shores in temperate latitudes where such grazers are rare. Most importantly, Brosnan (1992) predicted that competition among foliose algae would be unimportant on tropical shores with abundant grazing fish. Her studies were based on important generalizing models developed by Menge \& Sutherland $(1976,1987)$, and extensively critiqued by Underwood \& Denley (1984). Specific predictions made by Brosnan (1992) were: (1) in physically benign environments, consumer pressure will be the main structuring force in the community (here, 'benign' means that physical conditions vary little seasonally and that they are not extreme); (2) effects of predation will increase as trophic level decreases (this means that effects are greater at lower levels in the trophic hierarchy); (3) species at an intermediate trophic level will be regulated by both competition and predation; and (4) competition will occur among consumers that escape predation.

The shore at Praia Rasa in the Brazilian tropics supports a lush cover of foliose sessile species (Sgrott Sauer Machado et al. 1992). The conditions are benign with little seasonal variation in moderate water and air temperatures. The slope is very gentle and wave action is never strong. Herbivorous fish are abundant (authors' pers. obs.). According to the predictions of Brosnan's (1992) model, such conditions should result in sites of heavy predation and little competition. However, the first observation of lush cover by sessile species suggested that the community at Praia Rasa does not conform to the predictions.

Here we report on experiments done to determine the effects of (1) consumer pressure and (2) competition as factors maintaining community organization at Praia Rasa. We were particularly interested in using the results to test Prediction 1 of Brosnan (1992), as presented above.

\section{MATERIALS AND METHODS}

Study site. The shore investigated is located ca $150 \mathrm{~km}$ east of Rio de Janeiro at Praia Rasa, Búzios, Brazil $\left(22^{\circ} 44^{\prime} \mathrm{S}, 41^{\circ} 51^{\prime} \mathrm{W}\right)$. Basic information on the shore is given in our earlier work (Sgrott Sauer Machado et al. 1992). The substratum is continuous and mainly formed of Precambrian gneiss. The water is normally quite turbid because of sediment from a river mouth located $5 \mathrm{~km}$ from the site. The tides are semidiurnal and amplitudes vary between 0.8 and $1.0 \mathrm{~m}$. Water temperatures vary between 20.5 and $26^{\circ} \mathrm{C}$ and air temperatures from 16 to $28^{\circ} \mathrm{C}$. The average salinity is $34.7 \%$. Praia Rasa is unaffected by cold water upwelling which is characteristic of this stretch of coastline (Yoneshigue 1985). There are no sources of pollution

In the lower intertidal zone there are large patches dominated by perennial plants (Hypnea cervicornis, $H$. musciformis and Acanthophora spicifera) and colonial sessile coelenterates (Zoanthus sp.). Other patches are dominated by the casts of a sessile polychaete from the genus Phragmatopoma. We worked only within the first 2 patch types. Higher on the shore, there are distinct zones of mussels, barnacles and fucoid algae.

The site is visited by fishermen, but the only species taken from the benthos is the large mussel Perna perna found on the mid shore. None of the plants, herbivores or carnivores included as independent or dependent factors in our study were collected by fishermen.

Consumer species. A list of macro- and mesoherbivores (sensu Brawley \& Xiugeng 1987) is shown in Table 1. The abundant consumers were herbivores Note however, that polychaete worms were abundant and not included as experimental factors in this work.

Rough estimations of herbivore abundances were required to decide which consumers should be manipulated in experiments. Species which never foraged in our experimental area, or were very rare, were not considered. Very approximate estimates of herbivore abundances were made as follows. For crabs, a markrecapture technique was used. We captured as many crabs as possible in 3 of our experimental patches (1 Hypnea/Acanthophora patch and 2 Zoanthus patches) and marked each with a spot of nail polish. The crabs were released and, after $30 \mathrm{~min}$, we recaptured as many as possible. The ratio of marked to unmarked crabs allowed an estimation of crab densities in the patches (Krebs 1985).

Gastropod densities were simply counted within the experimental patches.

Amphipod densities were counted microscopically in 10 core samples ( $1 \mathrm{~cm}$ diameter) collected haphazardly in the Hypnea dominated patches. Amphipods were not normally found in the Zoanthus patches. 
Table 1 Macro-and meso-animal species occurrence in the intertidal region of Praia Rasa, Brazil

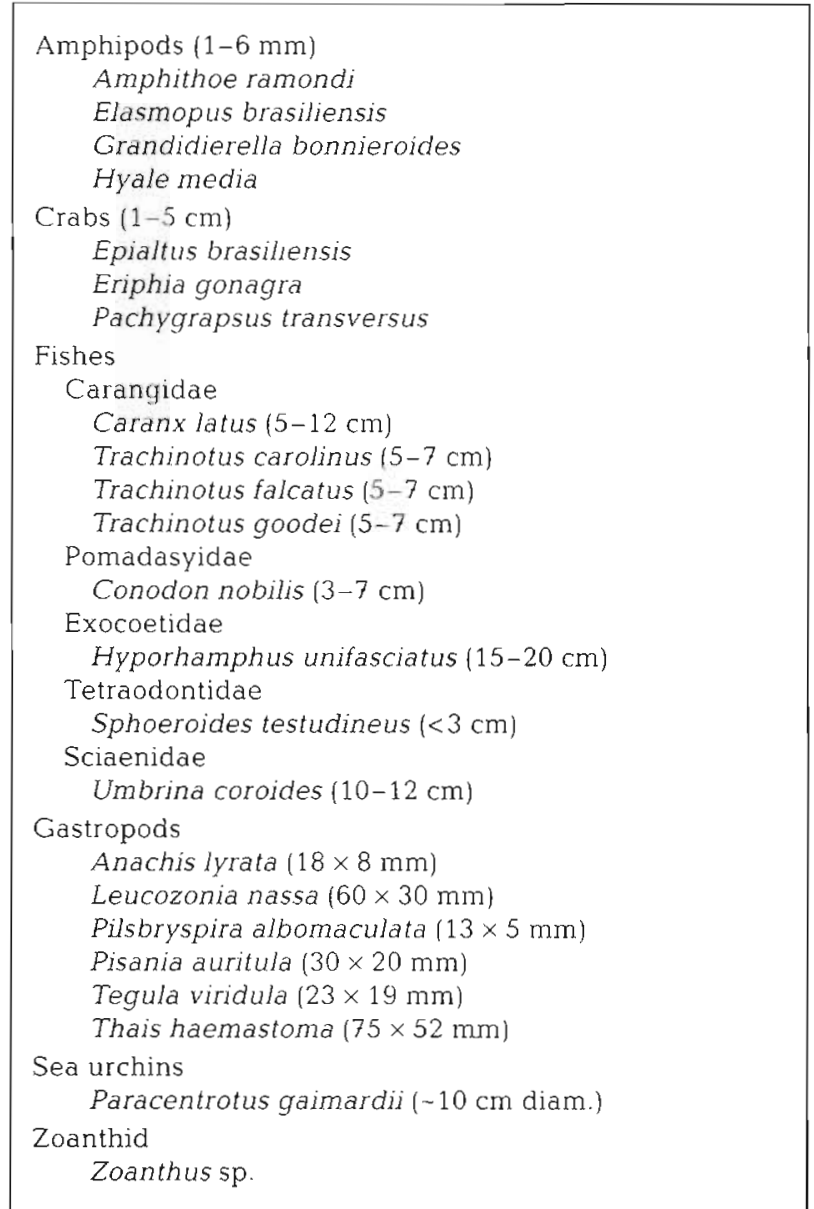

Herbivorous fish were abundant at the site. We captured them with nets on 3 occasions (including a nocturnal catch) and by hand in tide pools. No quantitative estimates were made, but stomach contents were analysed for food composition.

Sea urchins were present in grazing scars within both patch types. To determine how mobile these grazers were, we attached plastic straws to the spines and observed animals on 2 subsequent site visits.

Experimental design. A randomized block design was used. We worked within patches of (1) Hypneal Acanthophora (red algal turf) and (2) Zoanthus. In each case, 3 irregular patches were chosen as blocks. Patch dimensions are given in Table 2.

The experimental factors were (1) crabs, (2) fishes, (3) amphipods and (4) cover of basal sessile species. Separate experiments were done within patches of red algal turf and Zoanthus. Each factor was tested at 2 levels: present or absent (Table 3). The covers of basal sessile species were manipulated manually with scrapers. Consumers were manipulated in various ways.
Table 2. Sizes of experimental blocks (maximum width $\times$ maximum length). Blocks were established in 2 patch types in the community mosaic

\begin{tabular}{|c|c|c|}
\hline Patch type & Block number & Block size $(\mathrm{m})$ \\
\hline Hypnea/Acanthophora & A & $5.00 \times 7.40$ \\
\hline Hypnea/Acanthophora & $B$ & $3.70 \times 9.00$ \\
\hline Hypnea/Acanthophora & $\mathrm{C}$ & $4.30 \times 12.3$ \\
\hline Zoanthus & A & $3.76 \times 4.88$ \\
\hline Zoanthus & $B$ & $2.26 \times 4.80$ \\
\hline Zoanthus & C & $2.86 \times 4.58$ \\
\hline
\end{tabular}

Table 3. Combinations of treatment factors and devices used to implement them. Experiment was set up in 2 versions. In the first version the basal species was a turf of red algae (Hypnea/Acanthophora). In the second version, the basal species was a colonial coelenterate (Zoanthus). A: absent; P: present; $O$ : open cage; F: full cage; R: roof

\begin{tabular}{|cccccc|}
\hline & \multicolumn{3}{c}{$\begin{array}{c}\text { Treatment factors } \\
\text { Fish } \\
\text { Crabs Amphipods }\end{array}$} & $\begin{array}{c}\text { Basal } \\
\text { spp. }\end{array}$ & $\begin{array}{c}\text { Device } \\
\text { type }\end{array}$ \\
\hline P & P & P & P & O & A \\
P & P & A & P & O & P \\
A & A & P & P & F & A \\
A & A & A & P & F & P \\
A & P & P & P & R & A \\
A & P & A & P & R & P \\
P & P & P & A & O & A \\
P & P & A & A & O & P \\
A & A & P & A & F & A \\
A & A & A & A & F & P \\
A & P & P & A & R & A \\
A & P & A & A & R & P \\
\hline
\end{tabular}

Crabs were excluded with full cages $15 \times 15 \mathrm{~cm}$ by $10 \mathrm{~cm}$ high and constructed of $1 \mathrm{~mm}$ Nitex ${ }^{\mathrm{rm}}$ mesh on an aluminum angle frame (Parker et al. 1993). The full cages without crabs were tested against cages with holes in the side walls which allowed free ingress of crabs (procedural controls).

Fishes were excluded by fastening mesh roofs without sides 1 to $3 \mathrm{~cm}$ above the substratum. This allowed free access to crabs, but not to fish. The procedural controls were roofs with large holes cut in the mesh to allow fish grazing.

Amphipods were excluded with insecticide spray (tetramethrin and resmethrin) applied every $2 \mathrm{wk}$. The efficacy of this treatment was checked by censusing amphipods before and $1 \mathrm{wk}$ after spraying in 5 plots each measuring $10 \times 10 \mathrm{~cm}$. Unsprayed plots in all combinations of full and partial cages and roofs formed the procedural controls against which the sprayed plots were tested.

Certain treatment combinations were logistically impossible to set up. We were unable to include fish 
grazing while excluding crab grazing. In order to make the design orthogonal for analysis of variance (ANOVA), the factors 'crabs' and 'fishes' were combined in a single factor ('fast moving herbivores', hereafter FMH) with 3 levels: (1) crabs +, fishes +; (2) crabs +, fishes -; (3) crabs -, fishes -. For graphical analysis and for post hoc multiple range tests, crabs and fishes were treated separately. The 2 kinds of animals were subsumed into the factor FMH only in fully crossed ANOVAs and MANOVAs (multivariate analyses of variance).

Each treatment was represented once in each block. Within blocks, treatment assignment was random and each plot was at least $30 \mathrm{~cm}$ from its neighbour. The factor 'block' was included in the ANOVAs and MANOVAs in order to reduce error variance. Since there was no replication of treatments within blocks, it was not possible to discern Block $\times$ Treatment factor interactions. The assumption here is that, whereas the magnitude of treatment effects may have differed among blocks, the direction of the effects was similar across blocks.

The use of cages, roofs and insect spray carries the risks of artefacts. To check for artefacts with cages and roofs, we compared untreated plots with cages and roofs which were partially open so that herbivore access was allowed. In this way, it was possible to check for the effects of caging structures alone.

Checking for artefacts caused by insecticide spray was more complex. We wanted to know whether the spray had effects independently of amphipod presence or absence. This was not possible in a field experiment. Therefore a laboratory experiment was run. Twenty Ulva plants were placed in 4 tanks of running seawater and held for 1 wk. In 2 of the tanks, the plants were removed from the water and treated with spray once a day. After spraying, plants were held out of water for $1 \mathrm{~h}$. Controls were similarly treated, but not sprayed. Weight changes in treatment and control plants were compared to test for insecticide spray-induced artefacts.

Dependent variables and data collection. The entire experiment was installed in winter 1990 (August). Data were collected at the end of this month and then at $14 \mathrm{~d}$ intervals for 4 mo. Percentage covers of recruiting algae were estimated with a point intercept technique (Chapman 1989) in $10 \times 10 \mathrm{~cm}$ quadrats placed within the treatment plots. Data were scored from 30 random points among 100 within the gridded quadrats.

In the treatment plots set up within the red algal turf patches the abundances of the following species were analysed as response variables: (1) diatom film, (2) Enteromorpha sp., (3) Ulva sp., (4) Corallina officinalis and (5) members of the order Ceramiales (including Callithamnion, Centroceras, Ceramium, Chondria, Crouania, Dasya, Falkenbergia, Herposiphonia, Het- erosiphonia, Laurencia, Polysiphonia, Pterosiphonia and Spyridia). Falkenbergia is in the Bonnemaisoniales, but was included, for convenience, with members of the Ceramiales.

Since Corallina officinalis and members of the Ceramiales were so rare in the Zoanthus patches, we recorded only Groups (1), (2) and (3) above.

Data analyses. All of the raw data were angular transformed $(\arcsin \sqrt{Y})$ and subjected to MANOVA or MANCOVA to test for significant effects of treatment variables and their interactions. The repeated measurements in plots on successive sampling dates constituted the dependent vectors in the analyses. Time could not be treated as a factor in the analyses because observations were not independent. The use of MANOVA or MANCOVA avoids the problem of nonindependence, but makes interpretation of results complicated. Diatoms, Enteromorpha sp. and Ulva sp. were each present only during a portion of the experimental period. We excluded from the analysis sampling days when a species/form was absent in most treatments. Corallina officinalis and members of the Ceramiales were present throughout (including the first day). We included alternate sampling days in the analyses in these cases. The variable abundance of these forms among treatment plots on the first day might have influenced the analysis of treatment effects. We partialled out this confounding influence by MANCOVAs where cover on the first day was treated as the covariate.

The data were checked for multivariate normality and homoscedasticity with Hawkin's test (Johnson \& Field 1993). When the data failed to meet the test, the analysis was abandoned because multivariate analyses are very sensitive to departures from assumptions.

Before proceeding with MANCOVAs, the assumption of homogeneity of slopes was checked by an analysis for signficant interactions between the covariate and the experimental factors. Again, the test was abandoned when significant $(p<0.05)$ heterogeneity was detected, and all results presented here meet the assumption.

If a significant experimental effect was detected by multivariate analysis, univariate tests (ANOVA or ANCOVA) were run for each sampling day in question. When these tests revealed significant effects, Tukey-Kramer post hoc comparisons among treatment pairs were carried out.

Assumptions of normality and homoscedasticity for univariate analyses were tested by David's test and Cochran's tests, respectively (Sachs 1984). Between one-third and one-half of the data for each treatment combination in each experiment were not normally distributed. This is not a serious issue for robust univariate analyses (Zar 1984). However, when non- 
normality and heteroscedasticity occurred together, the test was abandoned. All of the univariate ANOVAs presented below meet the assumption of univariate homoscedasticity

All analyses were carried out with the SuperANOVA ${ }^{\text {rM }}$ package run on a Macintosh ${ }^{\text {TM }}$ computer.

\section{RESULTS}

\section{Herbivore abundances}

Using the mark-recapture technique, we estimated a very approximate density of $1 \mathrm{crab} \mathrm{m}^{-2}$. This may be an underestimate since some of the crabs were killed by the nail polish. The crabs were very active and obviously feeding in the study sites. Stomach contents of crabs from a nearby coast showed that the crabs are herbivorous, feeding mainly on foliose algae. The observations made it clear that crabs were sufficiently common and active to warrant inclusion as an experimental factor.

Amphipods were also very abundant. We estimated 8800 ind. $\mathrm{m}^{-2}$ (standard deviation, $\mathrm{SD}=11094$ ) and included these animals in our design.

Fish densities could not be adequately quantified. even on an approximate basis. However, they were clearly very abundant. We checked the stomach contents of 3 omnivorous species: Sphoeroides testudineus $(\mathrm{n}=2)$, Trachinotus carolinus $(\mathrm{n}=8$ ) and Umbrina coroides $(n=3)$. Algal material was common in all of them, including species found at all stages of the successional process (see Sgrott Sauer Machado et al. 1992 for successional sequence). All of the species were also carnivorous.

The densities of slow moving gastropods was so low ( $\left.\leq 1 \mathrm{~m}^{-2}\right)$, and they were so inactive, that they were not included in the experimental design. Sea urchins were also excluded since they stayed within their home scars, or very close to them and did not forage through the experimental areas (we never saw them near our plots through multiple site visits).
Based on these rough estimates of abundance, we decided to include fish, crabs and amphipods in our analysis of consumer species effects.

\section{Efficacy of treatments}

Scraping effectively removed $100 \%$ of Zoanthus or Hypnea/Acanthophora cover. We never found crabs or fish in the complete cages and assume that exclusion was complete. It was not possible to observe directly whether or not roofs excluded fish, but it is difficult to believe that larger or medium sized individuals would have gained access to substrate below the mesh.

The insecticide reduced amphipod populations to about $20 \%$ of control levels for several days after spraying

\section{Artefacts caused by cages, roofs and insecticide}

We were not able to detect artefact effects of cages or roofs on any of the dependent variables (MANOVAs, MANCOVAs and univariate ANOVAs, $p>0.05)$.

The spray used to control amphipods was found to significantly reduce the growth of Ulva in cultivation tanks (ANCOVA, $F_{1,15}=5.528, \mathrm{p}=0.033$ ).

\section{Treatment effects: within patches of Hypnea/ Acanthophora (red algal turf)}

A complete qualitative summary of treatment effects is given in Table 4.

Diatom film. Diatoms were especially abundant at early stages of succession and a 5-way MANOVA testing for treatment effects on their cover abundance was carried out on data collected in Weeks 2, 4 and 6 (Table 5). There were no significant treatment effects.

Enteromorpha. The mean cover of Enteromorpha in all treatments is shown in Fig. 1. This alga reached its

Table 4. Qualitative summary of treatment effects on 5 dependent variables in patches dominated by Hypnea/Acanthophora (red algal turf) or Zoanthus sp. (colonial coelenterate). NS: no significant effect; + : enhancement caused by treatment variable; -: neg ative effect of treatment variable

\begin{tabular}{|c|c|c|c|c|c|c|c|}
\hline \multirow[t]{3}{*}{ Treatment variable } & \multicolumn{7}{|c|}{ Dependent variable } \\
\hline & \multicolumn{2}{|c|}{ Diatoms } & \multicolumn{2}{|c|}{ Enteromorpha } & \multicolumn{2}{|c|}{ Ulva } & \multirow{2}{*}{$\begin{array}{l}\text { Ceramiales } \\
\text { H/A patch }\end{array}$} \\
\hline & H/A patch & Zoanthus patch & H/A patch & Zoanthus patch & H/A patch & Zoanthus patch & \\
\hline Basal species & NS & - & - & - & - & - & + \\
\hline Fast moving herbivores & NS & NS & NS & - & + & + & NS \\
\hline Amphipods & NS & NS & NS & - & NS & + & NS \\
\hline
\end{tabular}


Table 5. Effects of presence of 3 consumer groups and resident basal species on cover abundances of diatoms and Uly sp. in patches dominated by Hypneal Acanthophora. Results are for MANOVAs where dependent vectors were repeated cover value measurements over the sampling period. Data are angular transformed $(\arcsin V Y)$ cover estimates. Test statistic was Pillai's Trace. In all cases the assumption of multivariate normality and homoscedasticity has been met (Hawkins test). F: variance ratio; p: probability. Degrees of freedom

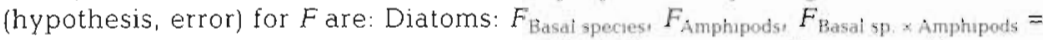
3,20, and 6,42 for all other estimates; Ulva: $F_{\text {Basal species, }} F_{\text {Amphipods, }} F_{\text {Basal sp. }}$ Amphipods $=4,19$, and 8,40 for all other estimates. $\cdots p<0.001, \cdots p<0.01$, $\cdot p<0.05,{ }^{n s} p>0.05$

\begin{tabular}{|c|c|c|c|c|}
\hline \multirow[t]{3}{*}{ Source of variation } & \multicolumn{4}{|c|}{ Algal type } \\
\hline & \multicolumn{2}{|c|}{ Diatoms } & \multicolumn{2}{|c|}{ Ulva } \\
\hline & $F$ & $p$ & $F$ & $\mathrm{p}$ \\
\hline Block & 1.051 & $0.4066^{\mathrm{ns}}$ & 2.709 & $0.0175^{\circ}$ \\
\hline Basal species (S) & 1.7066 & $0.1979^{\text {ns }}$ & 7.649 & $0.0008 \cdots$ \\
\hline Fast moving herbivores (FMH) & 1.811 & $0.1201^{\mathrm{ns}}$ & 4.019 & $0.0014 \cdots$ \\
\hline Amphipod (A) & 1.508 & $0.2431^{\mathrm{ns}}$ & 2.203 & $0.1075^{\mathrm{ns}}$ \\
\hline $\mathrm{S} \times \mathrm{FMH}$ & 0.842 & $0.5449^{n s}$ & 1.780 & $0.1101^{\mathrm{ns}}$ \\
\hline $\mathrm{S} \times \mathrm{A}$ & 1.029 & $0.4009^{\mathrm{ns}}$ & 1.052 & $0.4069^{n s}$ \\
\hline $\mathrm{FMH} \times \mathrm{A}$ & 0.340 & $0.9119^{\text {ns }}$ & 0.572 & $0.7945^{\mathrm{ns}}$ \\
\hline $\mathrm{S} \times \mathrm{FMH} \times \mathrm{A}$ & 1.268 & $0.2924^{n \varepsilon}$ & 0.384 & $0.9229^{n s}$ \\
\hline
\end{tabular}

UIva. The cover abundance of this species in all treatments is shown in Fig. 2. A 5-way MANOVA on data collected in Weeks 8 through 14 showed signficant direct effects for the FMH grazer group and for the presence or absence of red algal turf (Table 5). There were no significant interactions among treatment factors. Univariate ANOVAs on treatment effects were done on data collected in Weeks 8 through 12. Unacceptable heteroscedasticity (Cochran's test) invalidated an analysis of the fourteenth week's data. The results are consistent with the MANOVA. FMH $\left(F_{2,22} \geq\right.$ 6.745, $p \leq 0.0052$ ) and red algal turf $\left(F_{1,22} \geq 18.938, \mathrm{p} \leq 0.0003\right)$ only had significant main effects. Overall, the analyses show that UIva abundance is suppressed by red algal turf. Surprisingly, crabs and fishes had an enhancing effect on the abundance of Ulva. In the plots from which red algal turf

peak about 1 mo after the experiment was started. We used a MANOVA to test for treatment effects across the second, sixth, tenth and fourteenth weeks (Table 6). Enteromorpha was absent in 5 of the 6 treatments with red algal turf cover. These zero values preclude inclusion of basal species as a treatment factor in a parametric analysis, but, obviously, this red algal turf has a highly inhibitory effect on the development of Enteromorpha (Fig. 1). We analysed for consumer species effects in treatments from which red algal turf had been removed. There were no significant consumer effects (Table 6). had been removed, the abundance of Ulva increased with increasing frequency of grazers in the $F M H$ group. Depending on the date, Ulva cover was 2- to 8fold higher in plots with both crabs and fishes than in plots from which both of these herbivore groups had been excluded. The treatment which included crabs, but excluded fishes, had intermediate abundances of UIva. In treatments which included red algal turf, there was also a large difference between plots in which crabs and fishes were included and those plots in which these animals were excluded. FMH grazers consistently enhanced Ulva.

Table 6 . Effects of presence of 3 consumer groups (within 1 level of substrate type) on cover abundances of Enteromorpha sp., Ceramiales and Corallina officinalis in patches dominated by Hypnea/Acanthophora. Presence of resident basa.l species is not included as a factor because of unacceptable multivariate heteroscedasticity and non-normality. Results are for MAN(C)OVAs where dependent vectors were repeated cover values over the sampling period. Data are angular transformed (arcsin $\checkmark Y$ ) cover estimates. Test statistic was Pillai's Trace. For MANCOVA, the assumption of homogeneity of slopes was met. Covariates are cover values on first day of sampling. In all cases the assumption of multivariate normality and homoscedasticity has been met (Hawkins test). F: variance ratio; p: probability. Degrees of freedom (hypothesis, error) for $F$ are: Enteromorpha: $F_{\text {Amphipod }}=4,7$, and 8,16 for all other estimates; Ceramiales: $F_{\text {Amphipods }}$ and $F_{\text {xovarnate }}=4,6$, and 8,14 for all other estimates; Coralluna officinalis:

$F_{\text {Amphipods }}$ and $F_{\text {covariate }}=3,7$, and 6,16 for all other estimates. $\cdots p<0.001, \cdots p<0.01, \cdot p<0.05,{ }^{n s} p>0.05$. na: not applicable

\begin{tabular}{|c|c|c|c|c|c|c|}
\hline \multirow[t]{2}{*}{ Source of variation } & \multicolumn{4}{|c|}{$\begin{array}{l}\text { Algal type } \\
\text { Ceramiales }\end{array}$} & \multicolumn{2}{|c|}{ Coralluna officinalis } \\
\hline & $F$ & $\mathrm{p}$ & $F$ & $\mathrm{p}$ & F & $\mathrm{p}$ \\
\hline Block & 5.006 & $0.0030^{\cdots}$ & 0.752 & $0.6481^{\mathrm{ns}}$ & 1.746 & $0.1745^{\mathrm{ns}}$ \\
\hline Covariate & na & - & 0.414 & $0.7938^{\mathrm{ns}}$ & 0.426 & $0.7404^{\mathrm{ns}}$ \\
\hline Fast moving herbivores (FMH) & 2.055 & $0.1048^{\text {ns }}$ & 1.251 & $0.3411^{\mathrm{ns}}$ & 0.458 & $0.8293^{\mathrm{ns}}$ \\
\hline Amphipods (A) & 1.441 & $0.3152^{n s}$ & 1.137 & $0.4211^{1 \mathrm{~s}}$ & 0.213 & $0.8844^{\mathrm{ns}}$ \\
\hline $\mathrm{FMH} \times \mathrm{A}$ & 0.579 & $0.7806^{\mathrm{ns}}$ & 0.772 & $0.6325^{\text {ns }}$ & 0.285 & $0.9357^{\text {nis }}$ \\
\hline
\end{tabular}




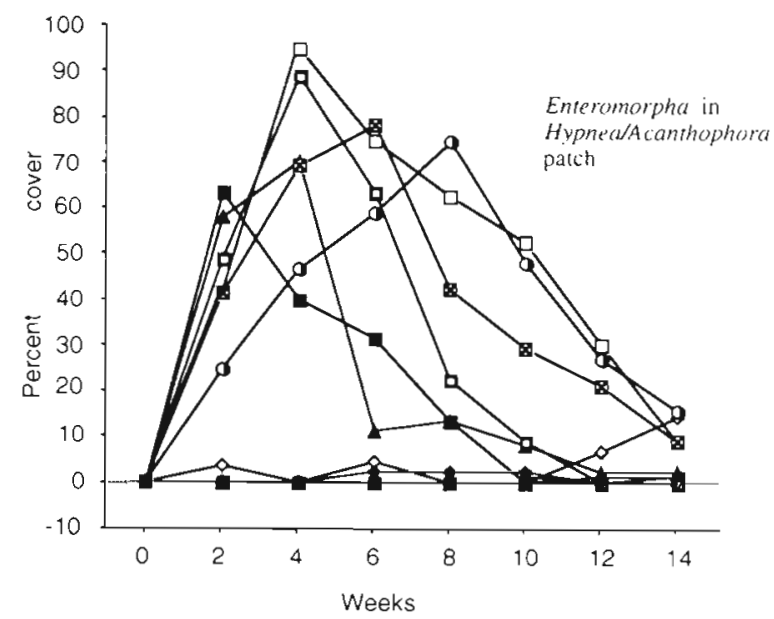

\begin{tabular}{|c|c|c|c|c|c|}
\hline & & Fish & Crab & Amphipod & Substrate \\
\hline \multirow{6}{*}{ 己े } & $x$ & Present & Present & Present & Hypnea/Acanthophora \\
\hline & 0 & Present & Present & Absent & Hypnea/Acanthophora \\
\hline & - & Absent & Absent & Present & HypnealAcanthophora \\
\hline & $\diamond$ & Absent & Absent & Absent & Hypnea/Acanthophora \\
\hline & + & Absent & Present & Present & Hypnea/Acanthophora \\
\hline & $\bullet$ & Absent & Present & Absent & Hypnea/Acanthophora \\
\hline \multirow{6}{*}{ 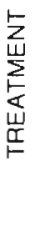 } & $\mathbf{\square}$ & Present & Present & Present & Rock \\
\hline & $\Delta$ & Present & Present & Absent & Rock \\
\hline & $\square$ & Absent & Absent & Present & Rock \\
\hline & 0 & Absent & Absent & Absent & Rock \\
\hline & $\mathbf{\square}$ & Absent & Present & Present & Rock \\
\hline & $\mathbf{8}$ & Absent & Present & Absent & Rock \\
\hline
\end{tabular}

Fig. 1 Percentage cover of Enteromorpha in 12 different treatments in Hypnea/Acanthophora blocks. Values are means ( $\mathrm{n}=3$ ). Observations started in October 1990. Variances are analysed in Table 6

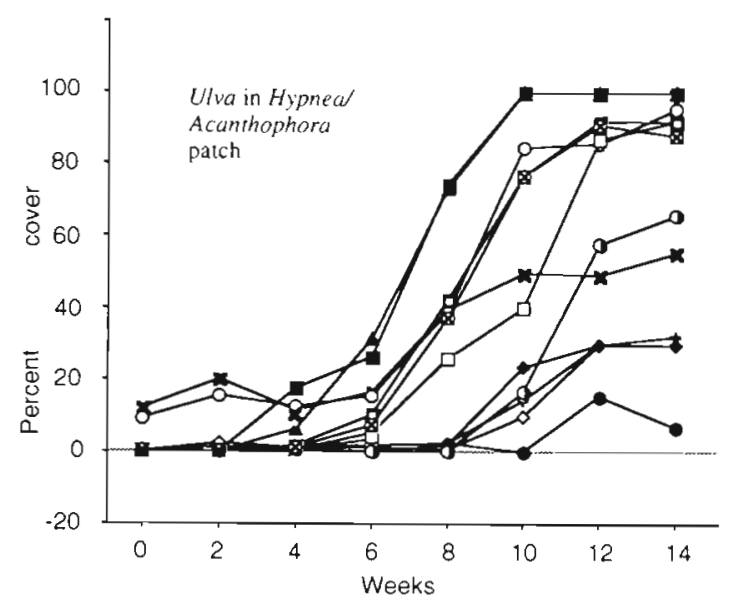

Fig. 2. Percentage cover of Ulva in 12 different treatments in Hypnea/Acanthophora blocks. Values are means ( $\mathrm{n}=3$ ). Observations started in October 1990. Variances are analysed in Table 5. Symbols as in Fig. 1
Ceramiales. The cover values for Ceramiales in all treatments are shown in Fig. 3. Ceramiales were either absent or at very low abundances in treatments where the substrate was rock (red algal turf removed). Obviously there was a very strong substrate effect. However, the variance structure of the full data set precludes parametric analysis. For this reason, we carried out a MANCOVA on the effects of consumer groups in plots where red algal turf was present (Table 6). There were no significant effects of consumers on the cover abundances of Ceramiales across the entire sampling period.

Corallina officinalis. The cover values of Corallina officinalis in each treatment are shown in Fig. 4 . The statistical analysis (Table 6) was identical to that for Ceramiales, and again, no significant effects of consumers were found. Substrate clearly had an overwhelming effect. Corallina cover values were either zero or close to zero in the absence of a turf of Hypnea/ Acanthophora.

\section{Treatment effects: within patches of Zoanthus}

Diatom film. The percentage cover of diatoms in all treatment combinations in Zoanthus patches is shown in Fig. 5. Diatoms appeared only in plots where Zoanthus was absent and analyses for consumer effects were done only for this level of substrate type. A MANOVA showed no significant effects of consumers on diatom cover across Weeks 2, 4 and 6 (Table 7).

Enteromorpha. The cover abundance of Enteromorpha is shown in Fig. 6. Again, substantial cover of this green alga developed only when Zoanthus was absent.

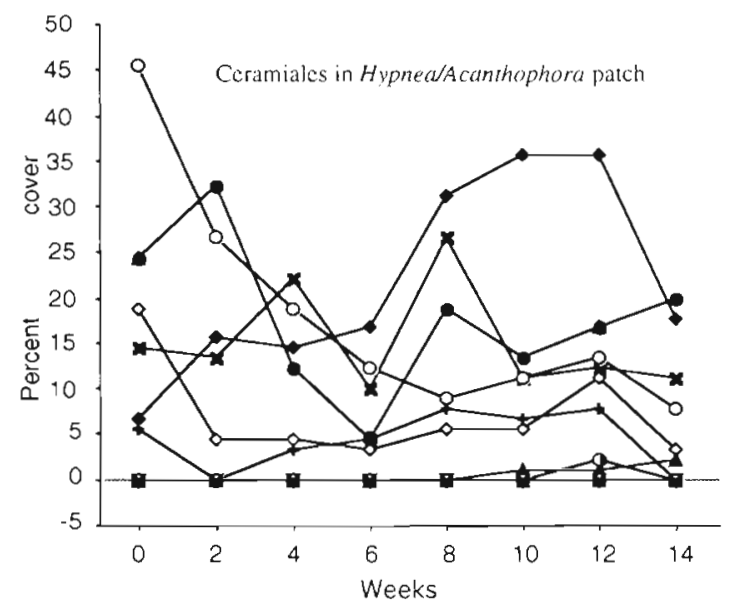

Fig. 3. Percentage cover of Ceramiales in 12 different treatments in Hypnea/Acanthophora blocks. Values are means $(\mathrm{n}=3)$. Observations started in October 1990. Variances are analysed in Table 6. Symbols as in Fig. 1 
Within this level of substrate type, we found a significant effect of amphipods, and grazers in the FMH group across Weeks 8 through 12 (MANOVA; Table 7). There were no significant interactions among the grazer groups

Univariate ANOVAs were done to identify significant consumer effects on each sampling day. Significant effects were found in Weeks 10 and 12. In Week 10, grazers in the FMH group significantly reduced the cover of Enteromorpha $\left(F_{2,10}=4.210, \mathrm{p}=0.0474\right)$. In Week 12, both amphipods and FMH grazers significantly reduced Enteromorpha cover $\left(F_{1,10}=21.957, \mathrm{p}=\right.$ $0.009 ; F_{2,10}=14.777, \mathrm{p}=0.0010$, respectively). There were no significant interactions between the grazer groups $\left(F_{2,10} \leq 0.951, p \geq 0.4186\right)$. The direction of consumer effects was consistent across species and days. Grazers reduced the abundance of Enteromorpha.

Significant pairwise differences between treatment combinations were revealed by post hoc tests in Week 12 only. The treatment with no grazers had a significantly higher Enteromorpha cover than the treatment with a full complement of grazers. Other treatments formed an intergrading series.

UIva. Cover developed only in the absence of Zoanthus (Fig. 7) and further analysis was restricted to this level of substrate type. A MANOVA across Weeks 8 through 12 showed a significant interaction between amphipods and FMH grazers on the abundance of Ulva (Table 7). Univariate ANOVAs also showed the same significant interaction effect in Weeks 10 and 12 $\left(F_{2,10}=6.633, p=0.0147 ;\right.$ and $F_{2,10}=4.542, p=0.0395$, respectively).

The significant interaction between the 2 grazer groups may be interpreted as follows. When amphi-

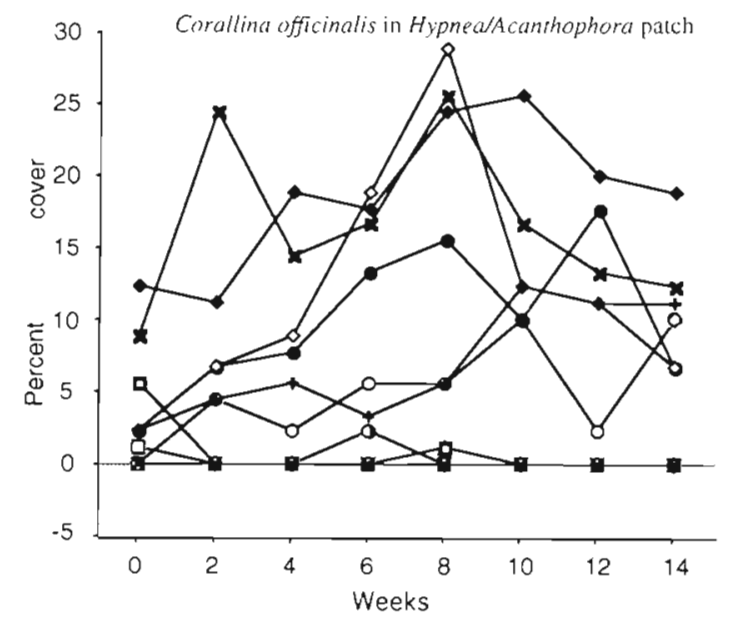

Fig. 4. Percentage cover of Corallina officinalis in 12 different treatments in Hypnea/Acanthophora blocks. Values are means $(n=3)$. Observations started in October 1990 . Variances are analysed in Table 6. Symbols as in Fig. 1 pods were present, the cover of Ulva was higher than when they were absent in 2 circumstances: (1) when crabs and fishes were present, or (2) when fishes were absent but crabs were present. However, Ulva cover was higher when amphipods were absent than when they were present, providing fishes and crabs were also absent.

Overall, the greatest development of Ulva occurred when Zoanthus was absent, and herbivores were present. Post hoc tests on data for Weeks 10 and 12 show that 3 treatments were significantly different from all others. These 3 treatments had 2 or 3 grazer groups (among fishes, crabs and amphipods) and had significantly higher Ulva cover than other treatments with fewer classes of grazers.

\section{DISCUSSION}

We tested for the effects of 3 main experimental factors on 8 sets of dependent variables (Table 3 ). Pre-emptive competition (detected as a response to

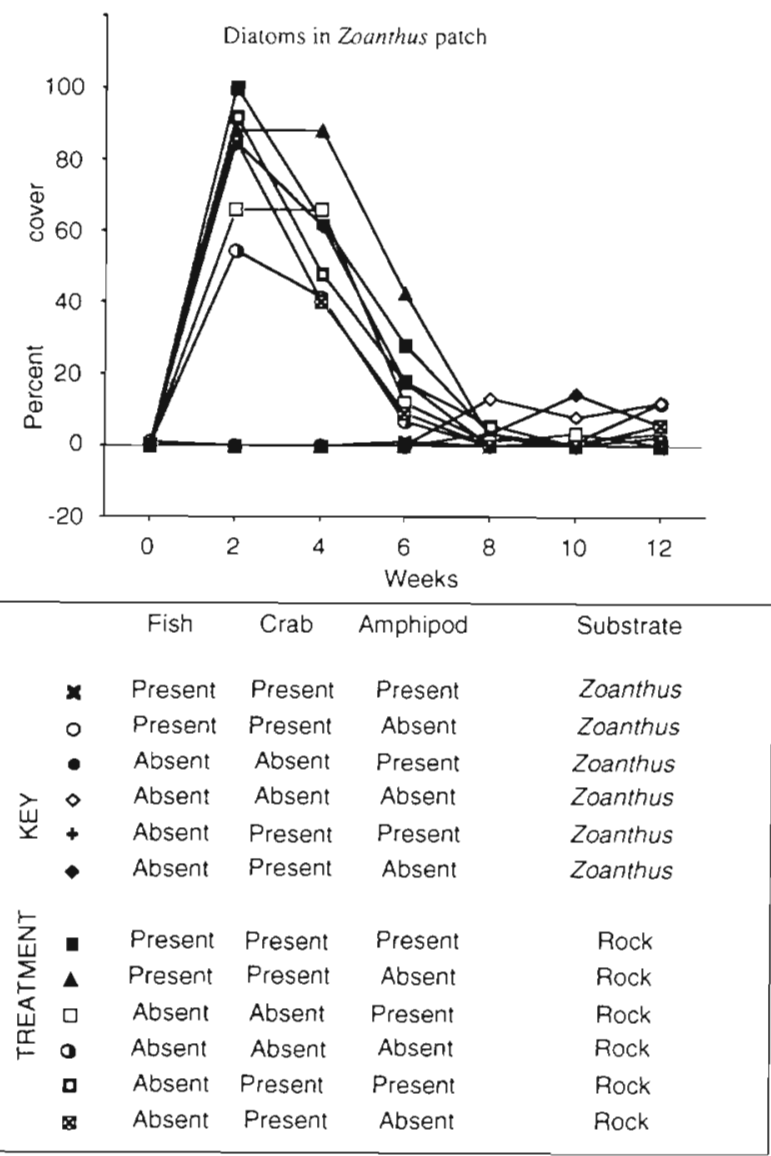

Fig. 5. Percentage cover of diatoms in 12 different treatments in Zoanthus blocks. Values are means $(n=3)$. Observations started in October 1990. Variances are analysed in Table 7 


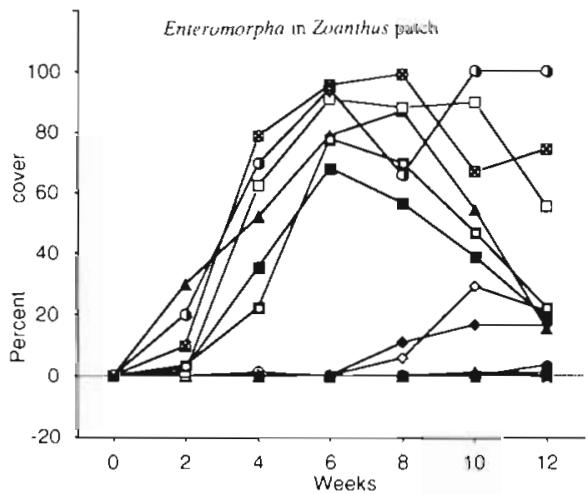

Fig. 6. Percentage cover of Enteromorpha in 12 different treatments in Zoanthus blocks. Values are means $(n=3)$. Observations started in October 1990. Variances are analysed in Table 7 . Symbols as in Fig. 5

presence or absence of basal species) had a major effect in all but 1 case. Most effects of consumer species were not significant. Of 16 data sets involving herbivores, 11 were not significant (Table 4). Further, the effects of grazers were not consistent. Herbivores had no significant effects on Enteromorpha abundance in clearings made in red algal turf patches, but, in similar clearings made in Zoanthus patches, grazers reduced the cover of Enteromorpha. In contrast, cover of Ulva was enhanced by fishes and crabs in both patch types. Amphipods also increased the abundance of Ulva, but only in clearings in Zoanthus patches. We conclude that competition for space among algae was a more important determinant of community structure than grazing in the tropical system we studied.

The mechanism by which grazers frequently enhanced the abundance of Ulva (Table 4) is unknown. Interpretation is especially difficult because significant effects on Enteromorpha, a closely related form, were always negative. Positive effects of grazers on ephe-

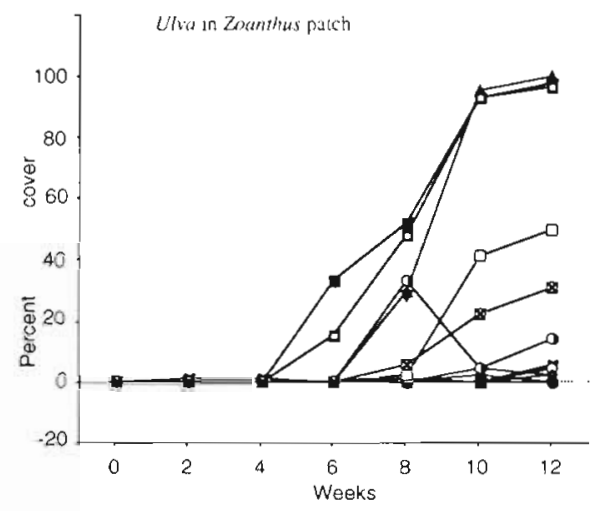

Fig. 7 Percentage cover of Ulva in 12 different treatments in Zoanthus blocks. Values are means $(n=3)$. Observations started in October 1990. Variances are analysed in Table 7 Symbols as in Fig. 5

meral algae have been noted before (Chapman 1989), but they remain an enigma.

The major weakness of this study is the artefact caused by insecticide spray used to control amphipod densities. The spray reduced the growth of Ulva in culture tanks. It may well have reduced the cover abundances of dependent variables in the main experiment. The field experiment demonstrated that when amphipods have a significant effect, it can be negative (Table 3). Since the spray also has a potentially negative effect on algal cover, the artefact will reduce the power of tests for negative amphipod effects. Conversely, the artefact will exaggerate the positive grazing elfects of amphipods.

Within the 2 patch types (red algal turf and Zoanthus), we studied the effects of grazers in a successional series of species which developed after scraping (when basal species were removed), and in mature stands which were not scraped. Diatoms, Enteromorpha and UIva developed in sequence after scraping Consumer effects were variable among these early

Table 7 . Effects of presence of 3 consumer groups (within 1 level of substrate type) on cover abundances of diatoms, Enteromorpha sp. and Ulva sp. in patches dominated by Zoanthus sp. Presence of resident basal species is not included as a factor because of unacceptable multivariate heteroscedasticity and non-normality. Results are for MANOVAs where dependent vectors were repeated cover values over the sampling period. Data are angular transformed (arcsin $\sqrt{ }$ Y) cover estimates. Test statistic was Pillai's Trace. In all cases the assumption of multivariate normality and homoscedasticity has been met (Hawkins test). F: variance ratio; p: probability. Degrees of freedom (hypothesis, error) for $F$ are: $F_{\text {Block }}=6,18$, and 3,8 for all other variance ratios. $\cdots p<0.001, \cdots p<0.01, \cdot p<0.05,{ }^{n<p}>0.05$

\begin{tabular}{|c|c|c|c|c|c|c|}
\hline \multirow[t]{2}{*}{ Source of variation } & \multicolumn{6}{|c|}{ Algal type } \\
\hline & $F$ & $p$ & $F$ & $p$ & $F$ & $\mathrm{p}$ \\
\hline Block & 1.600 & $0.2043^{n s}$ & 4.253 & $0.0077^{\cdots}$ & 2.489 & $0.0624^{\mathrm{ns}}$ \\
\hline Fast moving herbivores (FMH) & 1.110 & $0.3949^{\text {ns }}$ & 2.746 & $0.0449^{\circ}$ & 2.142 & $0.0984^{\text {ns }}$ \\
\hline Amphipods (A) & 2.477 & $0.1 .357^{\mathrm{ns}}$ & 7.910 & $0.0089 \cdots$ & 4.120 & $0.0485^{\circ}$ \\
\hline $\mathrm{FMH} \times \mathrm{A}$ & 1.270 & $0.3194^{\mathrm{ns}}$ & 0.971 & $0.4725^{\text {ns }}$ & 2.850 & $0.0394^{\circ}$ \\
\hline
\end{tabular}


successional forms. They had no effects on diatoms, and had contrasting effects on the 2 leafy green algae There were no significant grazer effects on mature stands of basal species.

Our overall results strongly contrast with those from the Bay of Panama (Menge \& Lubchenco 1981, Menge et al. 1983, 1985, 1986a, b, Lubchenco et al. 1984). These workers found a predominance of crustose algae in the mid and low zones of the intertidal region. Consumer exclusion experiments resulted in a 60 -fold increase in foliose algal abundance. These results show clearly the importance of predation at this site. However, no explicit experiments were done to test for competitive interactions. Indirect evidence indicated interference competition among algal crusts. Some species were able to overgrow others and this can certainly indicate the presence of competitive asymmetry. The fact that the algal crusts were overgrown by foliose species when consumers were excluded led Menge et al. (1986b) to conclude that predation is the dominant structuring force, not competition.

In a later work, Menge (1991) performed stepwise multiple regression analyses to determine the percentage of variance in the abundance of each dominant sessile species explained by recruitment, predation, herbivory, competition for space, etc at sites on the northeast coast of the USA and at Taboguilla Island in Panama. Interestingly, although competition was included as a factor for the analysis of New England (USA) data, it was not included in the analysis for the tropical site (Panama). So there is still no quantitative assessment of basal species competition for the Bay of Panama equivalent to our data from Brazil. Nevertheless, it seems quite certain that the communities at the 2 sites are structured in fundamentally different ways. This means that it is not possible to generalize from Taboguilla to all tropical locations.

Our data may be compared with the predictions of Brosnan (1992) for tropical rocky intertidal shores (see 'Introduction'). Although herbivorous fish were abundant at our site, they were not able to reduce algal cover to produce a bare shore or one dominated by algal crusts. Indeed, we found that fish can have positive rather than negative effects (Table 4). Although consumers were common at Praia Rasa, they were not the main structuring element in the community

The shore community we studied was very patchy on a scale of meters, contrary to the predictions of Brosnan (1992). We found very patchy communities on all of the shores of the Cabo Frio region of Brazil (authors' unpubl, obs.). Finally, we determined that competition between basal species is the most important ecological process on the shore at Praia Rasa. even though herbivores were abundant. The impact of herbivores cannot be predicted from their abundance.
Acknowledgements. The field work was carried out from the Insitituto de Estudos do Mar Almirante Paulo Moreira in Arraial do Cabo and we thank Commandant Emmanuel de Almeida Gama and his staff for their assistance. We are particularly grateful to Drs Y Yoneshigue and J. Valentin without whom we could not have completed the study, Marcelo Machado was extremely helpful in the field, in the organization of the data and in the statistical analysis. We thank him for his work. Much of the funding was provided through grant A6497 from the Natural Sciences and Environmental Research Council of Canada to A.R.O.C. Additional funds came from the Comissào Interministereal de Recursos do Mar (CIRM) in Brazil. Scholarship money for K.R.S.S.M. came in part from Coordenação de Aperfeiçoamento de Pessoal de Nivel Superior (CAPES) and Conselho Nacional de Desenvolvimento Científico e Tecnológico (CNPq). R.C. was supported by a grant from $\mathrm{CNPq}$. We thank these funding agencies

\section{LITERATURE CITED}

Brawley SH, Xiugeng F (1987) Studies of mesoherbivory in aquaria and in an unbarricaded mariculture farm on the Chinese coast. J Phycol 23:614-623

Brosnan DM (1992) Ecology of tropical rocky shores: plantanimal interactions in tropical and temperate latitudes. In: John DM, Hawkins SJ, Price JH (eds) Plant-animal interactions in the marine benthos. Clarendon Press, Oxford, p 101-131

Chapman ARO (1989) Abundance of Fucus spiralis and ephemeral algae in a high eulittoral zone: effects of grazers, canopy and substratum type. Mar Biol 102:565-572

Johnson CR, Field CA (1993) Using fixed-effects model multivariate analysis of variance in marine biology and ecology. Oceanogr Mar Biol A Rev 31:177-221

Krebs CJ (1985) Ecology. The experimental analysis of distribution and abundance. Harper \& Row, New York

Lubchenco J, Menge BA, Garrity SD, Lubchenco PJ, Ashkenas LR, Gaines SD, Emlet R, Lucas J, Strauss S (1984) Structure, persistence and role of consumers in a tropical. rocky intertidal community (Taboguilla Island, Bay of Panama). J Exp Mar Biol Ecol 78:23-73

Menge BA (1991) Relative importance of recruitment and other causes of variation in rocky intertidal community structure. J Exp Mar Biol Ecol 146:69-100

Menge BA, Ashkenas LR, Matson A (1983) Use of artificial holes in studying community development in cryptic marine habitats in a tropical intertidal region. Mar Biol 77 . $129-142$

Menge BA, Lubchenco J (1981) Community organization in temperate and tropical intertidal habitats: prey refuges in relation to consumer pressure gradients. Ecol Monogr 51 $429-450$

Menge BA, Lubchenco J, Ashkenas LR (1985) Diversity, heterogeneity and consumer pressure in a tropical intertidal community. Oecologia 65:394-405

Menge BA, Lubchenco J, Ashkenas LR (1986a) ExperimentaI separation of effects of consumers on sessile prey in the low zone of a rocky shore in the Bay of Panama: direct and indirect consequences of food web complexity. J Exp Mar Biol Ecol 100:225-269

Menge BA, Lubchenco J, Gaines SD, Ashkenas LR (1986b) A test of the Menge-Sutherland model of community organization in a tropical rocky intertidal food web. Oecologia $71: 75-89$ 
Parker T, Johnson C, Chapman ARO (1993) Gammarid amphipods and littorinid snails have significant but different effects on algal succession in littoral fringe tidepools. Ophelia 38:69-88

Sachs L (1984) Angewandte Statistik. Springer, Berlin

Sgrott Sauer Machado K, Chapman ARO, Coutinho R (1992) Patch structure in a tropical rocky shore community in Brazil: a mosaic of successional states? Ophelia 35: $187-195$

Underwood AJ, Denley EJ (1984) Paradigms, explanations and generalizations in models for the structure of untertidal communities on rocky shores. In: Strong DR, Sim-

This article was presented by G. C. Harding (Senior Editorial Advisor), Dartmouth, Nova Scotia, Canada berloff DS, Abele LG, Thistle AB (eds) Ecological communities: conceputal issues and the evidence. Princeton University Press, Princeton, NJ, p 151-180

Williams GA (1994) The relationship between shade and molluscan grazing in structuring communities on a moderately exposed tropical rocky shore. J Exp Mar Biol Ecol 178:79-95

Yoneshique Y (1985) Taxonomie et écologie des algues marines dans la région de Cabo Frio (Rio de Janeiro, Brésıl). PhD dissertation. Université de Marseille II

Zar JH (1984) Biostatistical analysis. Prentice Hall, Englewood Cliffs, NJ

Manuscript first received: July 19, 1994

Revised version accepted: November 27, 1995 